\title{
Dilution and volatilization of groundwater contaminant discharges in streams
}

Aisopou, Angeliki; Bjerg, Poul Løgstrup; Sonne, Anne Thobo; Balbarini, Nicola; Rosenberg, Louise; Binning, Philip John

Published in:

Journal of Contaminant Hydrology

Link to article, DOI:

10.1016/j.jconhyd.2014.11.004

Publication date:

2015

Document Version

Peer reviewed version

Link back to DTU Orbit

Citation (APA):

Aisopou, A., Bjerg, P. L., Sonne, A. T., Balbarini, N., Rosenberg, L., \& Binning, P. J. (2015). Dilution and volatilization of groundwater contaminant discharges in streams. Journal of Contaminant Hydrology, 172, 71-83. https://doi.org/10.1016/j.jconhyd.2014.11.004

\section{General rights}

Copyright and moral rights for the publications made accessible in the public portal are retained by the authors and/or other copyright owners and it is a condition of accessing publications that users recognise and abide by the legal requirements associated with these rights.

- Users may download and print one copy of any publication from the public portal for the purpose of private study or research.

- You may not further distribute the material or use it for any profit-making activity or commercial gain

- You may freely distribute the URL identifying the publication in the public portal

If you believe that this document breaches copyright please contact us providing details, and we will remove access to the work immediately and investigate your claim 
Dilution and volatilisation of groundwater contaminant discharges in streams.

Angeliki Aisopou, Poul L. Bjerg, Anne T. Sonne, Nicola Balbarini, Louise Rosenberg and

\section{Philip J. Binning}

Department of Environmental Engineering, Technical University of Denmark, Miljoevej, building 113, DK - 2800 Kgs. Lyngby, Denmark

Corresponding author: Angeliki Aisopou, Department of Environmental Engineering, Technical University of Denmark, Miljoevej, building 113, DK - 2800 Kgs. Lyngby, Denmark, (angelina.aisopou@gmail.com)

Submitted to Journal of Contaminant Hydrology, June 2013

Final revisions October 2014 


\section{Abstract}

An analytical solution to describe dilution and volatilisation of a continuous groundwater contaminant plume into streams is developed for risk assessment. The location of groundwater plume discharge into the stream (discharge through the side versus bottom of the stream) and different distributions of the contaminant plume concentration (Gaussian, homogeneous or heterogeneous distribution) are considered. The model considering the plume discharged through the bank of the river, with a uniform concentration distribution was the most appropriate for risk assessment due to its simplicity and limited data requirements. The dilution and volatilisation model is able to predict the entire concentration field, and thus the mixing zone, maximum concentration and fully mixed concentration in the stream. It can also be used to identify groundwater discharge zones from in-stream concentration measurement. The solution was successfully applied to published field data obtained in a large and a small Danish stream and provided valuable information on the risk posed by the groundwater contaminant plumes. The results provided by the dilution and volatilisation model are very different to those obtained with existing point source models, with a distributed source leading to a larger mixing length and different concentration field. The dilution model can also provide recommendations for sampling locations and the size of impact zones in streams. This is of interest for regulators, for example when developing guidelines for the implementation of the European Water Framework Directive. 


\section{Keywords}

dilution, volatilisation, model, groundwater, contaminant, stream

\section{Introduction}

The discharge of contaminated groundwater into streams may impact surface water quality, with contaminant loads originating from contaminated sites e.g., chlorinated solvents and other xenobiotic organic compounds (Conant et al. 2004; Westbrook et al. 2005; Chapman et al. 2007) , old landfill sites (Milosevic et al. 2012) or agricultural application of pesticides (McKnight et al. 2012). Due to the implementation of the European Water Framework Directive (WFD) and the increasing exploitation of stream water and groundwater, an increasing effort is made to understand the linkage between these two systems and assesses the effect of groundwater contaminants on surface water ecosystems and chemical quality (Hancock 2002; McKnight et al. 2010; Schmidt et al. 2010; McKnight et al. 2012). Proper tools for quantification of pollutant transport from groundwater seepage into streams and the inherent transport and dilution are essential for risk assessment and management of groundwater - surface water systems affected by contaminated sites.

Mixing in rivers and streams has been actively studied since the middle of the $20^{\text {th }}$ century and many researchers have been interested in modeling the transport of pollutants. The mixing process of pollutants in natural rivers and streams is complicated due to irregularities of the velocity, bed configuration, river shape etc. Most existing modeling studies focus on predicting the pollutant transport from a point pollutant release, characterized by continuous or instantaneous discharge or injection of a known pollutant mass with a low or high (waste water discharge, individual jet) initial velocity (Sanders et al. 1977; Fischer et al. 1979; Rutherford 1994; Lung 1995; Kalinowska and Rowinski 2012). These models use the advection-dispersion equation to predict the concentration distribution in the stream from a point pollutant release and to describe the mixing 
length, i.e. the downstream distance required to ensure uniform concentration across the river, and have been proved to be suitable in many studies (e.g., Lung 1995; Pujol and Sanchez-Cabeza 2000; Jirka and Weitbrecht 2005). One-dimensional models have also been developed to cater for the retention of pollutant in so-called dead zones (e.g., Runkel 1998) and take into account the changes of the factors affecting the pollutant transport (such as water flow rate, channel width and depth and stream bed slope) along a short stream length (Ani et al. 2009). These models describe mixing from a single point discharge release and do not consider the groundwater discharge plume width and the spatial distribution of the source along the stream. Since a distributed groundwater discharge source is very different from a point source, it is essential to incorporate these features in a model of the transport of pollutants in streams.

A limited number of recent studies deal with mixing downstream of multiport diffusers where pollutants are emitted in a line across a river (Zhang and Zhu 2011; Kalinowska and Rowinski 2012). For example, Zhang and Zhu (2011) studied the mixing downstream of a multiport diffuser in a wide shallow river. They tested the sensitivity of the modeling results to different initial spatial distributions of the pollutant in the vertical and lateral direction (homogeneous versus Gaussian concentration distributions), and showed that it had little effect on the results. However, the location of pollutant emission in the river, the spatial concentration distribution along the river (in the longitudinal direction) and the small velocity of discharge, which are characteristics of the groundwater seepage, are not considered in this model.

A model that predicts the pollutant dillution and volatilisation in a stream due to contaminated groundwater discharge is currently unavailable. In contrast to the point pollutant release and the multiport diffuser, the effluent in the groundwater seepage scenario enters the stream as a continuous source from a larger area, most likely from the side of the stream or half of its bottom and with a very small velocity and thus small initial dilution. In this study we aim to develop an 
analytical model for groundwater contaminant discharge mixing in a stream that considers transport, dilution and volatilisation processes. The model should be used in a regulatory context for risk assessment where simple screening models with limited data requirement are necessary (e.g., Chambon et al. 2011). The solution of Fischer (1979) for point pollutant release is modified to include volatilisation and all the conditions necessary to describe the concentration distribution of contaminated groundwater recharges into streams. It considers a range of boundary conditions enabling the risk assessment of various practical cases; for example different locations of groundwater seepage in the stream and different spatial concentration distributions of the pollutant along the groundwater seepage zone. The paper focusses on describing various options for the solution for its application to the groundwater discharge problem.

Field experimental studies have attempted to identify the surface water - groundwater interaction zones, quantify the inflow (Westbrook et al. 2005; Milosevic et al. 2012), and study the processes in the sediment bed during groundwater seepage (e.g., Conant et al. 2004; Bianchin et al. 2006; Chapman et al. 2007; Ellis and Rivett 2007; McKnight et al. 2010; Milosevic et al. 2012). In field studies the contaminant discharged from a groundwater plume was rarely detected in the stream due to rapid dilution by clean stream water and there is little published work on the resultant concentration distribution along the stream. In this study the developed models are compared to the field data provided by McKnight et al. (2010) and Nielsen et al. (2014) from two Danish streams. The applicability of the models for location of water quality sampling points and risk assessment in streams exposed to groundwater contamination is discussed with respect to current EU regulations, uncertainty, and potential for further model development.

\section{Conceptual model}


Figure 1a illustrates the conceptual model for the physical system considered in this study, where a groundwater plume of width equal to $W_{\text {plume }}$ is discharged into a stream of depth $d$ and width $W$. The model aims to predict contaminant concentration in the stream.

The groundwater plume can be discharged along half of the bottom of the stream (Figure 2a), or along a length of the stream's bank (Figure 2b). Numerical simulations were performed to investigate what is the location of the groundwater plume discharge in typical conditions. The governing parameters affecting whether the plume is discharged at the bank or through the stream bed are the aquifer depth and hydrogeology, the recharge rate, and the contaminated source location. A 2-D model of the catchment of the stream was developed to model the groundwater flow at steady state conditions using COMSOL Multiphysics 4.3, a finite element tool. Figure 3a shows the conceptual model and boundary conditions used. The simulations were repeated for different stream depths and widths, recharge rates and catchment sizes representing a range of typical values for streams and aquifers (further details in supporting information). A sand aquifer was used with vertical and hydraulic conductivities of $10^{-4}$ and $10^{-5} \mathrm{~m} / \mathrm{s}$, respectively. The depth of the aquifer did not affect the results. Figure 3b shows the streamlines discharging to the stream through the bank (white streamlines) and the stream bed (black streamlines). For each scenario, $\mathrm{x}_{\text {critical }}$ was estimated, where the $\mathrm{x}_{\text {critical }}$ is the maximum distance from the stream of a contaminated source where the plume resulting from the source will discharge to the stream through its bank (Figure 3b). For typical conditions, $\mathrm{x}_{\text {critical }}$ is always larger than $0.5 \mathrm{~km}$, i.e. any contaminated source located closer than $0.5 \mathrm{~km}$ from the stream will discharge to the stream through its bank (see Supporting Information S1 for more details). Since many contaminated sources posing a risk to streams are located closer than $0.5 \mathrm{~km}$ from the stream, the model considering the plume discharge from the bank is the most appropriate in most scenarios and was applied in the model. 
The scenario where the groundwater seepage is from a length of the bank ( $W_{\text {plume}}$, Figure $2 \mathrm{~b}$ ) was compared with point discharge at the bank of the stream (Figure 2c). Finally, for the case (Figure $2 \mathrm{~b}$ ) where the plume was discharged over a width $\left(W_{\text {plume}}\right)$ the effect of the mass distribution of the plume was studied (Figure 4), with the mass being distributed: i) uniformly over the plume's width, ii) as a Gaussian distribution, and iii) non-uniformly (Figure 3).

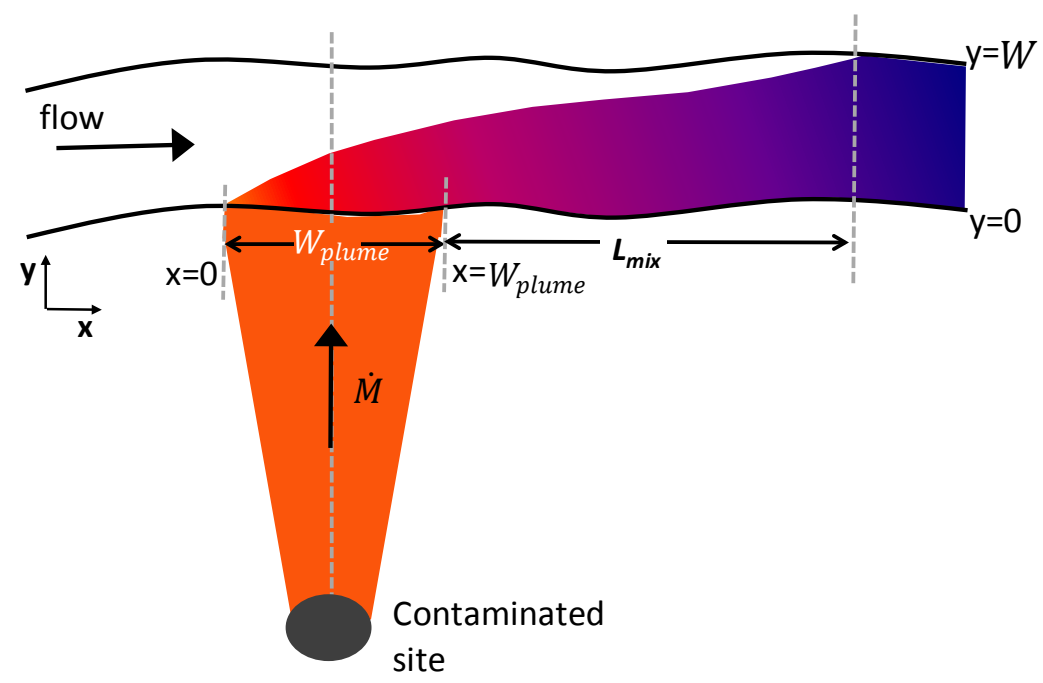

Figure 1. Conceptual model of the physical system analyzed in this study: groundwater plume of width equal to $\mathrm{W}_{\text {plume }}$ discharged in the stream of width $\mathrm{W}$.

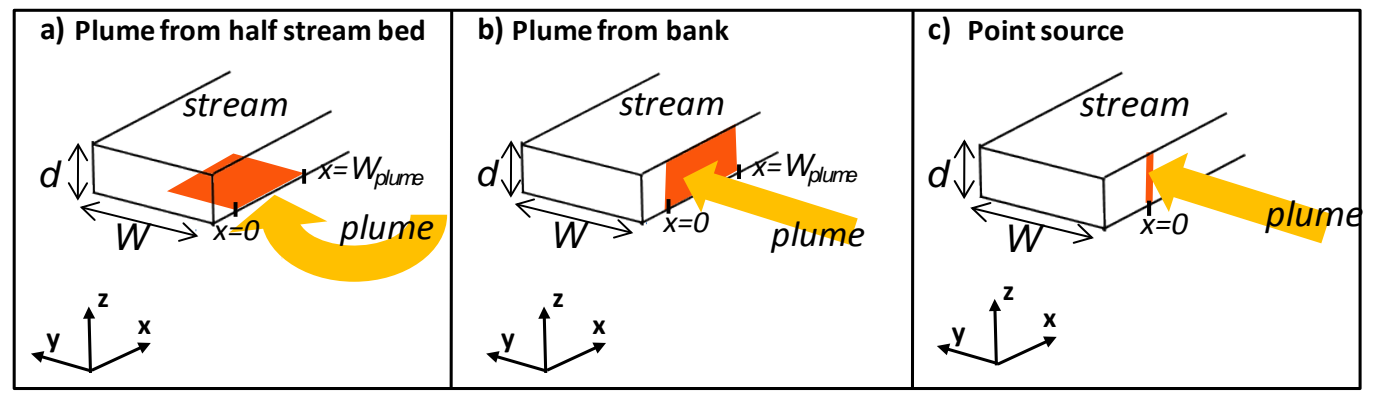

Figure 2. Conceptual models for groundwater plume discharged at: a) a point at the side of the stream $(x=0, y=0), b)$ along a length of the bank (plume width $=\mathrm{W}_{\text {plume}}$ ), and $\mathrm{c}$ ) along a length at the half stream bed. $\mathrm{x}=0$ is at the point located at the most upstream point of plume discharge. For a) and b) the concentration is assumed uniform in the vertical direction. 


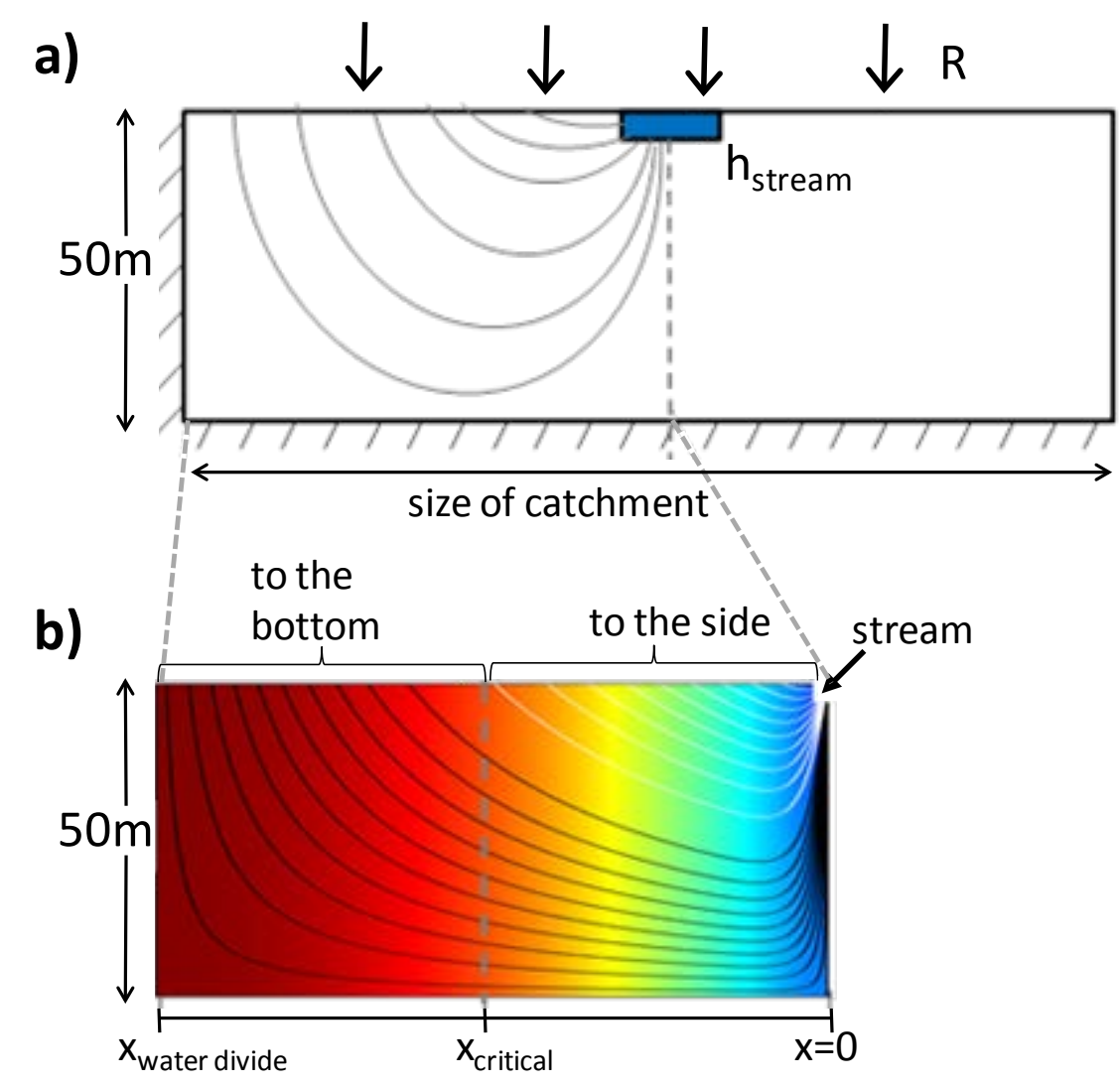

Figure 3. a) Conceptual model to test if groundwater reaches the stream from the bank or half the stream bed. b) Black and white streamlines show water discharging to the stream bed and the bank of the stream, respectively. Only half of the catchment is modeled due to symmetry. $\mathbf{x}_{\text {critical }}$ is the maximum distance from the stream that a contaminant at the surface will reach the stream from the side. 


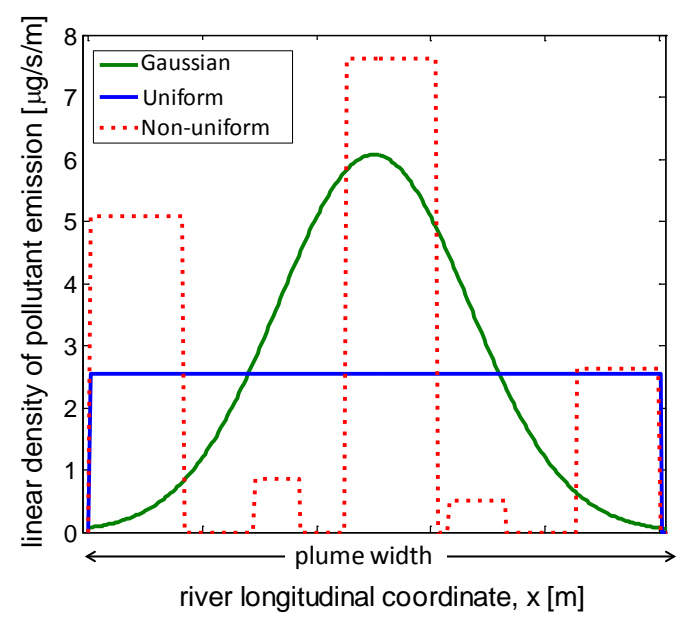

Figure 4. Contaminant plume discharged in the side of the stream; three mass discharge distributions are considered i) Gaussian, ii) uniform, and iii) non-uniform.

\section{Mathematical model}

A model was developed to estimate contaminant transport in streams where first order volatilisation is occurring. The process of volatilisation is described based on the two-film theory, which assumes that Fick's first law can be applied to estimate the flux of gas at the gas-liquid interface (Liss \& Slater, 1974). The mathematical model is based on the following set of assumptions: (i) the initial/ background concentration within the entire domain area of the stream is zero, (ii) the depth of the stream is small in comparison with the width, (iii) the cross sectional stream area is rectangular, (iv) the groundwater discharge to the stream is negligible compared to the flow of the water in the stream, (v) the initial concentration in air is zero.

For the majority of natural rivers and streams the depth of a river is small compared with its width or length; since the mixing time is proportional to the square of the length divided by the mixing coefficient, within a relatively short distance from the source, complete mixing in the vertical direction will be achieved (Fischer et al. 1979). Therefore the 2-D advection-dispersion model with first-order decay due to volatilisation, derived by depth averaging, is effective, in which 
only longitudinal and transverse mixing are considered (e.g., Ruthven 1971; Fischer et al. 1979; Elhadi et al. 1984; Zhang and Zhu 2011):

$$
\frac{\partial C}{\partial t}=\varepsilon_{l} \frac{\partial^{2} C}{\partial x^{2}}+\varepsilon_{t} \frac{\partial^{2} C}{\partial x^{2}}-u \frac{\partial C}{\partial x}-\mathrm{K}_{\mathrm{V}} C
$$

where $\mathrm{K}_{\mathrm{V}}$ is the volatilisation constant, $u[\mathrm{~m} / \mathrm{s}]$ is the velocity and $\varepsilon_{l}\left[\mathrm{~m}^{2} / \mathrm{s}\right], \varepsilon_{t}\left[\mathrm{~m}^{2} / \mathrm{s}\right]$ are the transverse and longitudinal mixing coefficients, respectively (Fischer et al., 1979).

\subsection{Volatilisation}

Volatilisation is a process based on partitioning of a substance between liquid and gas phase (Mendoza and Gillham, 1996) and is affected by the conditions in the environment such as wind, temperature and water turbulence. Different models describing volatilisation from a stream to the atmosphere were reviewed (Southworth (Southworth, 1979), Cadena (Cadena et al. (1984), Thyssen (Thyssen et al., 1987; Dahi et al., 1989), Langbein and Durum (Trapp and Harland, 1995) and AQUATOX (Park and Clough, 2012)). The review had the aim to select a model with a low number of parameters required and a large applicability at different hydrogeological units. The research showed that the AQUATOX model requires parameters which are hard to estimate such as the air concentration. Similarly, Cadena is based on a parameter which is available for a small amount of pollutants and in situ measurements with a tracer are needed to define it. Langbein and Durum applies for small streams and disregards the effect of wind in the volatilization process. Finally, Southworth can be used for a bigger variety of hydrological units such as rivers, lakes and deltas, and is widely used. Therefore, Southworth was implemented in this study. The Southworth model is based on the two-film theory and assumes a first order exponential decay. The volatilisation rate is constant and is described as: 


$$
\mathrm{K}_{\mathrm{V}}=\frac{\mathrm{K}_{L}}{d}
$$

where $d[\mathrm{~m}]$ is the depth of the stream and $\mathrm{K}_{L}[\mathrm{~m} / \mathrm{s}]$ is the overall mass transfer coefficient defined as:

$$
\mathrm{K}_{\mathrm{L}}=\frac{\mathrm{K}_{H}^{\prime} \cdot \mathrm{k}_{g} \cdot \mathrm{k}_{l}}{\mathrm{~K}_{H}^{\prime} \cdot \mathrm{k}_{g}+\mathrm{k}_{l}}
$$

where $\mathrm{K}_{H}^{\prime}=\mathrm{K}_{H} /(\mathrm{R} \cdot \mathrm{T}), \mathrm{R}[\mathrm{L} \cdot \mathrm{atm} /(\mathrm{mol} \cdot \mathrm{K})]$ is the gas constant, $\mathrm{T}[\mathrm{K}]$ is the temperature and $\mathrm{K}_{H}$ is Henry's Law constant. The temperature dependence of the Henry's Law Constant can be described by:

$$
\mathrm{K}_{\mathrm{H}}=\exp \left(A-\frac{B}{\mathrm{~T}}+C \cdot \ln (\mathrm{T})\right)
$$

where the coefficients $A, B$ and $C$ are available in the literature (Chen et al, 2012). $\mathrm{k}_{g}[\mathrm{~m} / \mathrm{s}]$ and $\mathrm{k}_{l}[\mathrm{~m} / \mathrm{s}]$ are the gas and liquid phase exchange constants, respectively that for a reference temperature equal to $25^{\circ} \mathrm{C}$ can be estimated as (Southworth, 1979):

$$
\begin{gathered}
\mathrm{k}_{g}=1.1375 \cdot\left(\mathrm{v}_{\text {wind }, 0.1}+u\right) \cdot \sqrt{\frac{18}{\mathrm{M}}} \\
\mathrm{k}_{l}=\mathrm{F} \cdot 0.2351 \cdot \frac{u^{0.969}}{d^{0.673}} \cdot \sqrt{\frac{32}{\mathrm{M}}}
\end{gathered}
$$

where $\mathrm{v}_{\text {wind, } 0.1}[\mathrm{~m} / \mathrm{s}]$ is the wind speed at $0.1 \mathrm{~m}$ height and can be estimated from the wind speed at $10 \mathrm{~m}$ height $\left(\mathrm{v}_{\text {wind,10 }}\right)$, which is often available (Trapp and Matthies, 1998). F is a function of $\mathrm{V}_{\text {wind,0.1 }}$ and is described by Trapp and Harland (1995) and MW is the molar weight of the compound. 
The model is valid for $\mathrm{v}_{\text {wind, } 0.1}$ lower than $5 \mathrm{~m} / \mathrm{s}$ which corresponds to a maximum $\mathrm{v}_{\mathrm{wind}, 10}$ equal to $10 \mathrm{~m} / \mathrm{s}$ (Trapp and Matthies, 1998). It is therefore possible to apply the model in Denmark where the annual average $\mathrm{v}_{\text {wind,10 }}$ equals to $5.8 \mathrm{~m} / \mathrm{s}$ (DMI, 2013).

\subsection{Point source discharged at the bank}

A rectangular stream of depth, $d[\mathrm{~m}]$ and width, $W[\mathrm{~m}]$ is assumed into which $\dot{M}$ units of mass per time is discharged. For the scenario where the groundwater is discharged at a point at the side of the stream ( $x=0$ and $y=0$, Figure 2a), the concentration $C\left[\mathrm{~kg} / \mathrm{m}^{3}\right]$ at any point $(x, y)$ downstream of the source can be determined by equation (1). The analytical solution of a similar differential equation to model multidimensional groundwater flow with longitudinal and transverse dispersion and first-order degradation was determined by Hunt (1978). The principle of superposition was used to sum the point discharge solutions to obtain a solution incorporating an areal mass discharge. The method is described by Fischer et al. (1979). Using Hunt's analytical solution and Fischer's method of superposition the concentration $C\left[\mathrm{~kg} / \mathrm{m}^{3}\right]$ at any point $(x, y)$ downstream of the source is:

$$
\begin{gathered}
C(x, y)=\frac{C_{m i x} Q \mathrm{e}^{\frac{x u}{2 \varepsilon_{l}}}}{2 d \pi \sqrt{\varepsilon_{l} \varepsilon_{t}}} \sum_{n=-\infty}^{\infty}\left\{\mathrm{K}_{0}\left[\frac{U}{2 \varepsilon_{l}} \sqrt{\left(x^{2}+\frac{\varepsilon_{l}}{\varepsilon_{t}}\left(y-2 n W-y_{0}\right)^{2}\right)}\right]\right. \\
\left.+\mathrm{K}_{0}\left[\frac{U}{2 \varepsilon_{l}} \sqrt{\left(x^{2}+\frac{\varepsilon_{l}}{\varepsilon_{t}}\left(y-2 n W+y_{0}\right)^{2}\right)}\right]\right\}
\end{gathered}
$$

where $x \in(0, \infty)$ and $y \in(0, W), \mathrm{K}_{0}$ is the zero-order modified Bessel function, $C_{\text {mix }}=\dot{M} / Q$ $\left[\mathrm{kg} / \mathrm{m}^{3}\right]$ is the fully mixed concentration in the stream, $Q\left[\mathrm{~m}^{3} / \mathrm{s}\right]$ is the flow, $U=\bar{u} \sqrt{\left(1+4 \varepsilon_{l} K_{V} / \bar{u}^{2}\right)}[\mathrm{m} / \mathrm{s}], \bar{u}=Q / W b[\mathrm{~m} / \mathrm{s}]$ is the mean velocity, $y_{o}$ is the y-location where the plume is discharged $\left(y_{o}=0\right.$ for the plume discharged at the bank), $\varepsilon_{t}=0.3 d u^{*}\left[\mathrm{~m}^{2} / \mathrm{s}\right]$ 
(Rutherford 1994) is the transverse mixing coefficient, which dominates the mixing process, $\varepsilon_{l}$ is the longitudinal mixing coefficient which can be set equal to the transverse mixing coefficient (Socolofsky and Jirka, 2005), $u^{*}=\sqrt{g d S}[\mathrm{~m} / \mathrm{s}]$ is the shear velocity, $g\left[\mathrm{~m}^{2} / \mathrm{s}\right]$ is the acceleration due to gravity and $S$ is the stream slope.

\subsection{Plume discharged over a length of the bank}

By using the principle of superposition, Equation (7) can be modified to account for the fact that contaminated groundwater is not discharged at a point, but instead is discharged over a length of the bank ( $W_{\text {plume }}$ ) (Figure $2 \mathrm{~b}$ ). The concentration distribution is described by a set of slugs each

distributed over a distance $d \xi$. Each slug contains a contaminant mass discharge $\dot{M}_{i}(\xi) d \xi$. The concentration distribution in the stream is derived using the principle of superposition (Fischer et al., 1979) to be:

$$
\begin{gathered}
C(x, y)=\int_{-\infty}^{\infty} \frac{C_{i}(\xi) Q \mathrm{e}^{\frac{x u}{2 \varepsilon_{l}}}}{2 d \pi \sqrt{\varepsilon_{l} \varepsilon_{t}}} \sum_{n=-\infty}^{\infty}\left\{\mathrm{K}_{0}\left[\frac{U}{2 \varepsilon_{l}} \sqrt{\left(x^{2}+\frac{\varepsilon_{l}}{\varepsilon_{t}}\left(y-2 n W-y_{0}\right)^{2}\right)}\right]\right. \\
\left.+\mathrm{K}_{0}\left[\frac{U}{2 \varepsilon_{l}} \sqrt{\left(x^{2}+\frac{\varepsilon_{l}}{\varepsilon_{t}}\left(y-2 n W+y_{0}\right)^{2}\right)}\right]\right\} d \xi
\end{gathered}
$$

where $C_{i}(\xi)=\dot{M}_{i}(\xi) / \bar{u} d W$. Equation 8 is the more general form and is able to account for more than one plume at the stream's bank; this is why the integration is done from -infinity to +infinity. For only one plume, the integration will be from 0 to $W_{\text {plume }}$ since the concentration is zero everywhere else. For most practical cases performing the summation for $-20<n<20$, will give results with an accuracy on the order of $10^{-4} \cdot C_{\text {mix }}$. However, for some stream types (such as wide and shallow streams with small mean flow, $\bar{u}<0.003 \mathrm{~m} / \mathrm{s}$ ) summing over a larger range of $n$ is 
necessary to obtain the correct concentration distribution. Performing the summation for $-150<$ $n<150$ will give results with an accuracy on the order of $10^{-4} \cdot C_{\text {mix }}$ for any stream type. The integration is performed only for $\xi<x$ i.e. for a given $x$, only the upstream $\xi$ are considered.

Equation (8) includes the product $\exp (z 1) \cdot \operatorname{besselk}(\mathrm{nu}, \mathrm{z} 2)$, where $z 1=x u / 2 \varepsilon_{l}$. In many case studies, the exponent $\left(x u / 2 \varepsilon_{l}\right)$ is very large. In order to overcome this problem in Matlab we use the definition of the Matlab modified Bessel function of second kind: besselk $(n u, z, 1)=$ $\operatorname{besselk}(n u, z) \cdot \exp (z)$, in order to replace the product $\exp \left(z_{1}\right) \cdot \operatorname{besselk}\left(n u, z_{2}\right)$ by:

$$
\exp \left(\mathrm{z}_{1}\right) \cdot \operatorname{besselk}\left(\mathrm{nu}, \mathrm{z}_{2}\right)=\exp \left(\mathrm{z}_{1}-\mathrm{z}_{2}\right) \cdot \operatorname{besselk}\left(\mathrm{nu}, \mathrm{z}_{2}, 1\right)
$$

By subtracting $z 2$ from $z 1$, in the term $\exp (z 1-z 2)$ the exponent in the exponential term is controlled and can always be evaluated numerically.

In Equation (8) $c(x, y)$ can be expressed as a function of 9 input parameters: i) the stream's discharge, $Q$, ii) depth, $d$, iii) width, $W$, iv) slope, $S, \mathrm{v}$ ) the plume's width, $W_{\text {plume }}$, vi) the mass discharge, $\dot{M}$ and the volatilisation rate, $K_{V}$ which if estimated with the Southworth model requires vii) the wind speed at $0.1 \mathrm{~m}$ height, viii) the Henry's Law Constant $K_{H}$ and ix) the molar weight of the compound (MW).

Using Equation (8), a vertical mixing model in which the plume is discharged over the whole width of the stream bed can be developed, by replacing the transverse direction, $y$ with the vertical direction $z$.

The developed model can be modified to account for an initial concentration in the stream $C_{o}$ by applying Equation (8) to $C-C_{o}$ instead of $C$. The background air concentration will always be negligible due to high dilution by diffusion and turbulence. 


\subsection{Initial concentration distribution over longitudinal direction}

$\dot{M}_{i}(x)$ in Equation (8) describes an arbitrary distributed source along the groundwater plume width. Three different longitudinal concentration profiles along the plume width were examined (Figure 3). Since the vertical mixing time is typically two orders of magnitude smaller than the transverse mixing time, a uniform concentration distribution can be assumed along the stream's depth (see section 3.5).

The first boundary condition assumed a uniform concentration distribution over the plume width, where $\dot{M}_{i}(x)$ is defined by:

$\dot{M}_{i}(x)=\dot{M} / W_{\text {plume }}$, for $0<x<W_{\text {plume }}$ and $\dot{M}_{i}(x)=0$, for $x>W_{\text {plume }}$

The second boundary condition assumed a Gaussian concentration distribution in the longitudinal direction over the plume width. For this scenario $\dot{M}_{i}(x)$ is defined by:

$$
\dot{M}(x)=\frac{\dot{M}}{\sqrt{2 \pi \sigma^{2}}} \exp \left[\frac{-(x-\mu)^{2}}{2 \sigma^{2}}\right]
$$

where $\mu$ is the mean and $\sigma$ is the standard deviation $\sigma=W_{\text {plume }} / 6$, assuming that the plume is spread over 6 standard deviations, where 6 standard deviations was chosen so that $99.9 \%$ of the mass is discharged over the width $W_{\text {plume }}$.

The third boundary condition assumed a non-uniform step distribution over the plume width (Figure 3), where the groundwater seepage was high over some parts of the bank and low over others. This is the most realistic scenario due to the heterogeneity of the groundwater plume or the heterogeneity of the aquifer. 


\subsection{Mixing length}

The downstream length at $\mathrm{y}=0$ for the concentration to be within $5 \%$ of its mean value everywhere in the cross section, i.e. complete mixing in the transversal direction (y-direction), for a point source is given by Fischer et al. (1979):

$$
L_{m i x \_p}=\frac{0.4 \bar{u} W^{2}}{e_{t}}
$$

The downstream length for complete mixing to be achieved in the vertical direction is $L_{v m i x \_p}=$ $\bar{u} d^{2} / e_{v}$, where $\varepsilon_{v}\left(\mathrm{~m}^{2} / \mathrm{s}\right)$ is the vertical mixing coefficient, $\varepsilon_{v}=0.067 d u^{*}$.

\subsection{Maximum concentration in the stream}

The maximum concentration reached in the stream when a plume with a uniform concentration distribution of width, $W_{\text {plume }}$ enters the stream from the side will always occur at the end of the plume width ( $\left.x=W_{\text {plume }}\right)$ and at the bank of the stream $(y=0)$. The concentration at this point can be estimated using Equation (8), as:

$$
C_{\text {max }}=C\left(W_{\text {plume }}, 0\right)=\int_{0}^{W_{\text {plume }}} \frac{c_{i}(\xi) Q \mathrm{e}^{\frac{x_{\text {plume }} u}{2 \varepsilon_{l}}}}{2 d \pi \sqrt{\varepsilon_{l} \varepsilon_{t}}} \sum_{n=-\infty}^{\infty}\left\{2 \mathrm{~K}_{0}\left[\frac{U}{2 \varepsilon_{l}} \sqrt{\left(x^{2}+\frac{\varepsilon_{l}}{\varepsilon_{t}}(-2 n W)^{2}\right)}\right]\right\} d \xi
$$

where $C_{i}(x)=M_{i}(x) / Q$, and $M_{i}(x)$ is the mass discharged by the contaminated plume. Performing the summation for $-150<n<150$ provides a solution with an accuracy of the order of $10^{-4} \cdot C_{\text {mix }}$ for any stream type. The integration is performed only for $\xi<x$, i.e. for a given $x$, only the upstream $\xi$ are considered. For non-uniform groundwater discharge distributions, the location of maximum 
concentration depends on the balance between the groundwater contaminant input and the mixing in the stream.

The analytical solution assumes that groundwater discharge only consists of a mass flux of contaminant to the stream and no accompanying water. Because of this, the concentration of contaminant in groundwater is not considered in the analytical solution and the $C_{\text {max }}$ concentration considers only the mass injected and the diffusion, dispersion and volatilization processes occurring in the stream. $C_{\max }$ will therefore be less than the concentration in the groundwater discharge.

\section{Field Studies}

The risk assessment model was applied to two examples of contaminated sites located close to streams: Grindsted stream Nielsen et al. (2014) and Skensved stream (McKnight et al. 2010). The two streams have different properties (Table 1). Grindsted stream is $10 \mathrm{~m}$ wide and $1.7 \mathrm{~m}$ deep and is contaminated by plume with chlorinated ethenes- including vinyl chloride (VC). Skensved stream is a very small stream, $1.4 \mathrm{~m}$ wide and $0.11 \mathrm{~m}$ deep and is contaminated by a trichloroethylene (TCE) plume. At both sites groundwater discharge zones have been characterised and concentrations in the stream determined at different locations along the stream at mid-width and mid-depth. The parameters used as input for the risk assessment model are shown in Table 1. In both cases the transverse mixing length is 5 times larger than the vertical mixing, therefore the 2-D advection-dispersion model, derived by depth averaging is effective. Both streams can be categorised as small streams, and since the Southworth model, which was used to evaluate the volatilisation constant was originally made for medium and large streams (Southworth, 1979), the Langbein and Durum model (Trapp and Harland, 1995) was also used to validate the Southworth 
model in case of a small stream. The two models results in volatilisation constants of the same order of magnitude and the same concentration distribution in the stream.

Table 1. Input parameters including stream and groundwater plume characteristics for application of the risk assessment model at Grindsted and Skensved.

\begin{tabular}{|c|c|c|c|c|}
\hline & Parameter & & Grindsted $^{\mathrm{a}}$ & Skensved $^{\mathrm{b}}$ \\
\hline \multirow{7}{*}{$\begin{array}{l}\text { Stream } \\
\text { parameters }\end{array}$} & $Q\left(\mathrm{~m}^{3} / \mathrm{s}\right)$ & Discharge & 1.6 & 0.0063 \\
\hline & $d(\mathrm{~m})$ & Depth & 1.7 & 0.11 \\
\hline & $W(\mathrm{~m})$ & Width & 10 & 1.4 \\
\hline & $S \%_{0}$ & Slope & 1.2 & 2.4 \\
\hline & $T\left({ }^{\circ} \mathrm{C}\right)$ & $\begin{array}{l}\text { Seasonally average } \\
\text { temperature }\end{array}$ & 9.3 & 16 \\
\hline & $\mathrm{V}_{\text {wind }, 10}(\mathrm{~m} / \mathrm{s})$ & $\begin{array}{l}\text { Seasonally average } \\
\text { windspeed at } 10 \mathrm{~m}\end{array}$ & 4.8 & 4.6 \\
\hline & $\begin{array}{l}\varepsilon_{t} \mathrm{~m}^{2} / \mathrm{s} \\
\varepsilon_{l} \mathrm{~m}^{2} / \mathrm{s} \\
\varepsilon_{v} \mathrm{~m}^{2} / \mathrm{s}\end{array}$ & $\begin{array}{l}\text { transverse, } \\
\text { longitudinal, } \\
\text { vertical mixing coefficient }\end{array}$ & $\begin{array}{l}0.08 \\
0.08 \\
0.01\end{array}$ & $\begin{array}{l}0.0017 \\
0.0017 \\
0.00033\end{array}$ \\
\hline \multirow[t]{5}{*}{$\begin{array}{l}\text { Groundwater } \\
\text { plume }\end{array}$} & $W_{\text {plume }}(\mathrm{m})$ & $\begin{array}{l}\text { Width of contaminated } \\
\text { plume }\end{array}$ & $150^{\mathrm{C}}$ & $250^{\mathrm{C}}$ \\
\hline & Contaminant & & vinyl chloride & TCE \\
\hline & $\dot{M}(\mu \mathrm{g} / \mathrm{s})$ & $\begin{array}{l}\text { Mass discharge in inflow } \\
\text { zone }\end{array}$ & $580^{d}$ & $130^{d}$ \\
\hline & $\mathrm{MW}(\mathrm{g} / \mathrm{mol})$ & Molar weight & 63 & 131 \\
\hline & $\begin{array}{l}A, \\
B, \\
C\end{array}$ & $\begin{array}{l}\text { Constants in Henry’s Law } \\
\text { Constant versus } \\
\text { Temperature correlation } \\
\text { (equation 4) }\end{array}$ & $\begin{array}{l}-132.4 \\
-3775 \\
20.36\end{array}$ & $\begin{array}{l}152.2 \\
10547 \\
-21.23^{\mathrm{e}}\end{array}$ \\
\hline
\end{tabular}

${ }^{\mathrm{a}}$ Nielsen et al. (2014), ${ }^{\mathrm{b}}$ McKnight et al. (2010), ${ }^{\mathrm{c}}$ estimated from field data, ${ }^{\mathrm{d}}$ best fit to data based on fully mixed stream concentrations using Southworth model, ${ }^{\mathrm{e}} \mathrm{Chen}$ et al. (2012)

\section{Application of risk assessment model for streams}

\subsection{Effect of area of groundwater discharge concentration distribution}


The effect of considering the length of the groundwater plume along the bank on the concentration distribution in the stream was examined by comparing the results with the point input case. A uniform concentration distribution was assumed along the bank.

Figure 5a-b show the concentration distribution in the Grindsted stream obtained for the two different discharge concentration distributions (Figure 2b and 2c). The point source model results in a very large concentration at the source $(x=0$ and $y=0)$ and a large variation in the concentration across the stream (Figure 5a and c). The behavior is very different to that observed when the length of the groundwater plume is taken into account (Figure 5b and c), and so does not describe the mixing due to groundwater discharge very well. The mixing length for the point source model obtained with Equation (11) is $L_{m i x_{-} p}=55 \mathrm{~m}$ implying that irrespective of the plume width, a fully mixed concentration is reached $55 \mathrm{~m}$ downstream the source. In contrast, the model assuming that the groundwater seepage occurs over a length at the bank (Figure 5b) takes into account the larger area over which the contaminated groundwater plume is discharged and result in the fully mixed concentration at $x_{m i x}=205 \mathrm{~m}$ downstream from the most upstream point of plume discharge (Figure 5d). The mixing length is at:

$$
x_{\text {mix }}=L_{\text {mix }} p+W_{\text {plume }}
$$

For small streams (e.g. Skensved) similar patterns were obtained to those shown in Figure 5, but the variation across the stream width was marginal due to faster mixing across the stream, and the concentrations observed in the stream were significantly higher due smaller dilution (lower flow). Equation (13) may lead to an overestimation of the mixing length since the most downstream portion of the groundwater mass discharge may only be a small fraction of the total discharge, so that complete mixing is not needed for the stream concentration to approach its mean (fully mixed) state. However, equation (13) is recommended for use by regulators, where a conservative approach is needed. 
To check the assumption of full vertical mixing, a vertical mixing model was developed where the plume enters through the bottom of the stream bed over the entire stream width. Results show that the concentration did not vary significantly with depth and that vertical mixing occurred almost instantaneously (results are not shown in the paper). Thus the scenario where the plume enters through the whole stream bed results in a fully mixed system both across and over depth.

a. Point source
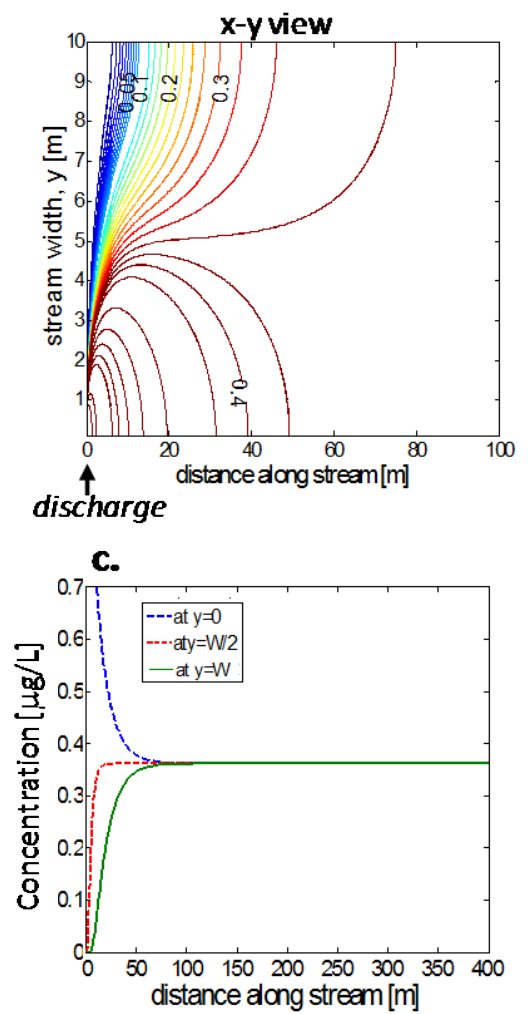

b. Plume from bank

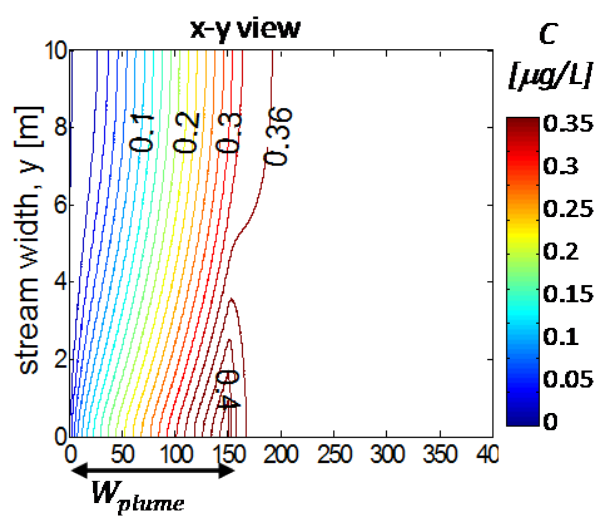

d.

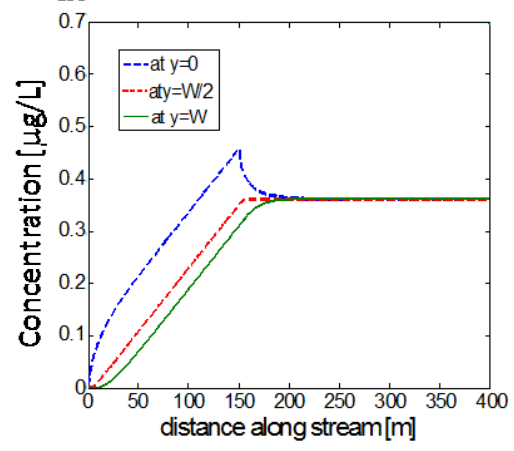

Figure 5. Vinyl chloride concentration distribution in Grindsted stream obtained when the contaminant is discharged at a point at the side of the stream $(x=0, y=0)(a)$, along a length of the bank $\left(W_{\text {plume }}\right)(b)$. $c-d$ show the concentration along the longitudinal direction $(x)$ at $y=0$ (bank where contaminant is discharged), $y=W / 2$ (middle of the stream) and $y=W$.

\subsection{Effect of initial concentration distribution of the contaminant plume}

For the scenario where the plume is discharged at the side of the stream, three different longitudinal concentration profiles along the plume width were examined: i) a uniform 
concentration distribution (Figure 6a), ii) a Gaussian concentration distribution (Figure 6b), and iii) a non-uniform distribution over the plume width (Figure 6c). The shape of the non-uniform distribution was chosen so that it gives the best fit to the field data. A uniform concentration distribution was assumed in the vertical.

Figure 6d-f show the vinyl chloride concentration distribution in the middle of the Grindsted stream and Figure 7d-f show TCE concentration distribution in the middle of the Skensved stream obtained with the three initial concentration distributions. All distributions in each stream resulted in the same fully mixed concentration, since the same total mass discharge was used. The biggest variation in concentration across the stream and the maximum concentration observed at the bank, $C_{\max }$ which is a useful indicator for assessing the vulnerability of the stream was obtained with the uniform concentration distribution (Figure 6e).

In order to assess the ability of the dilution model to describe groundwater contaminant discharge mixing in a stream and the effect of different initial concentration distributions, the concentrations in the middle of the stream obtained with the analytical model were compared to the published experimental data sets (McKnight et al. 2010; Nielsen et al. 2014). Figure 6g-i show the vinyl chloride concentration in the middle of the Grindsted stream and Figure 7g-i the TCE concentration in the middle of the Skensved stream, obtained experimentally and with the three initial concentration distributions. The analytical model is able to describe the main features of the contaminant concentration in the streams and is suitable for risk assessment. Volatilisation is very limited in the Grindsted case $\left(\mathrm{K}_{\mathrm{V}}=2.4 \cdot 10^{-6} \mathrm{~s}^{-1}\right)$ and the same concentration distribution was observed when volatilisation was neglected. In Skensved stream a decay is observed in the TCE concentration data measured in the field, due to volatilization of the compound in the stream (McKnight et al. 2010). Volatilization is more pronounced compared to the Grindsted stream because of the shallow depth of the stream, which enhances mass transfer to the atmosphere. When 
the volatilisation was estimated with the Southworth model $\left(\mathrm{K}_{\mathrm{V}}=7 \cdot 10^{-5} \mathrm{~s}^{-1}\right)$ and a mass of 130 $\mu \mathrm{g} / \mathrm{s}$, the maximum concentration in the stream compared well with the observed data. However, the concentration distribution along the river was overestimated, but clearly showed the effect of volatilisation. The best fit was achieved by fitting both the value of the volatilisation constant and the mass discharge $\left(\mathrm{M}=195 \mu \mathrm{g} / \mathrm{s} ; \mathrm{K}_{\mathrm{V}}=2 \cdot 10^{-4} \mathrm{~s}^{-1}\right.$, see Figure $\left.7 \mathrm{~g}-\mathrm{i}\right)$.

For both case studies little differences are shown among the results obtained with the three groundwater discharge distributions, indicating that detailed knowledge of the distribution may not be very important for risk assessment at an initial stage.

Later, if field data for the concentration distribution in the stream is available, the model can be used to infer the points of groundwater input and construct the non-uniform groundwater discharge distribution. The slope of the stream concentration curve (Figure 7i) provides information on the contaminant mass input at any given point (Figure 7c). Thus an additional practical use of the model is that it can be used to analyse the distribution of mass discharge along the stream bank, and can therefore be used to determine sampling locations in detailed monitoring campaigns, and motivate more sophisticated modelling approaches before implementation of remediation strategies. 
a. UNIFORM

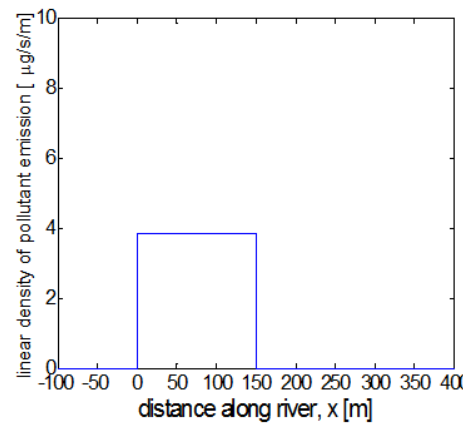

d.
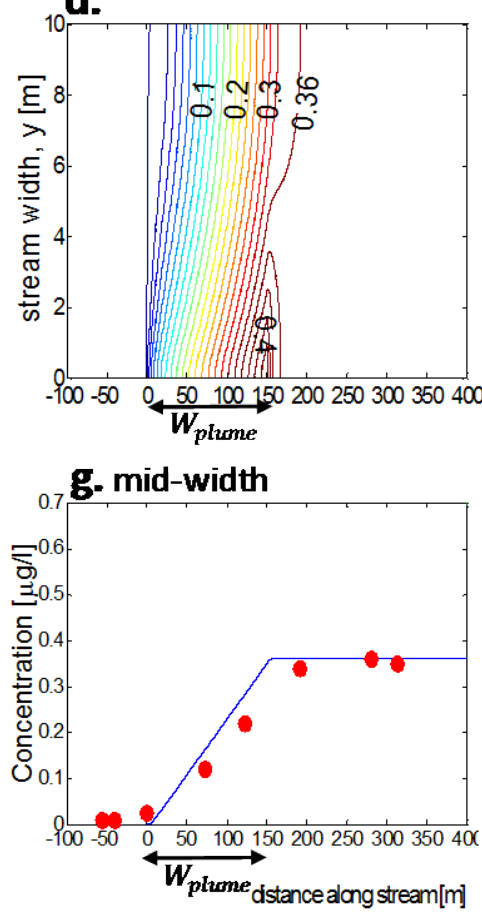

b. GAUSSIAN

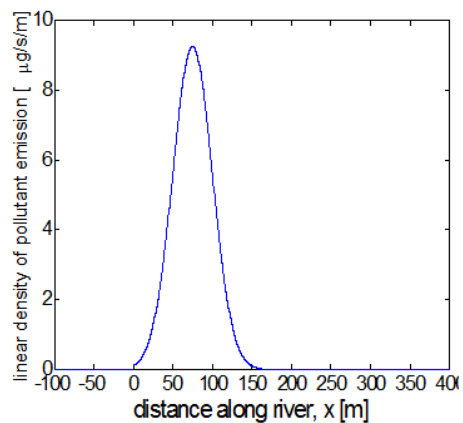

${ }_{10} \mathbf{e}$.

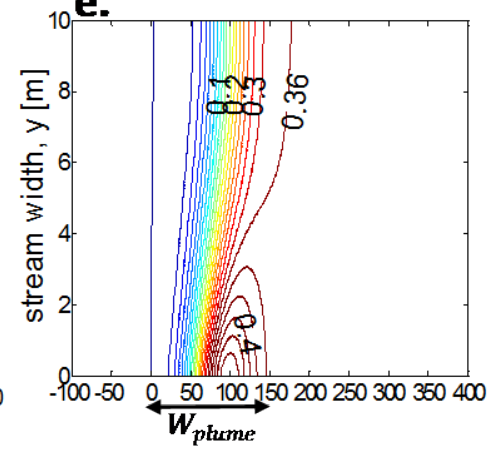

h. mid-width

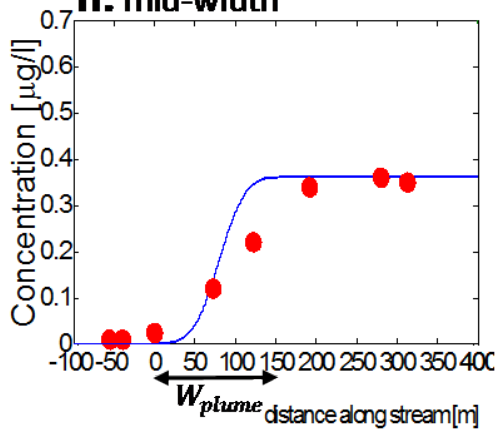

C. NON-UNIFORM
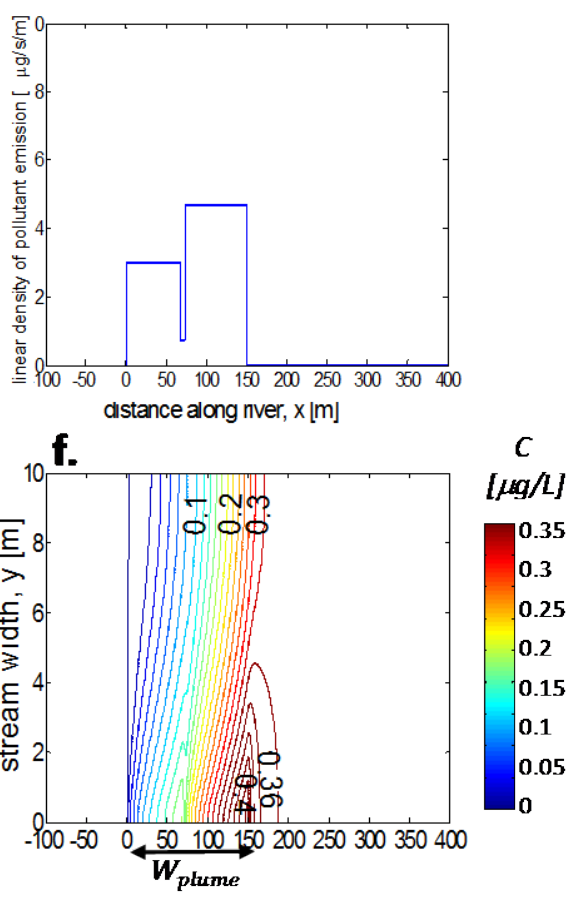

i. mid-width

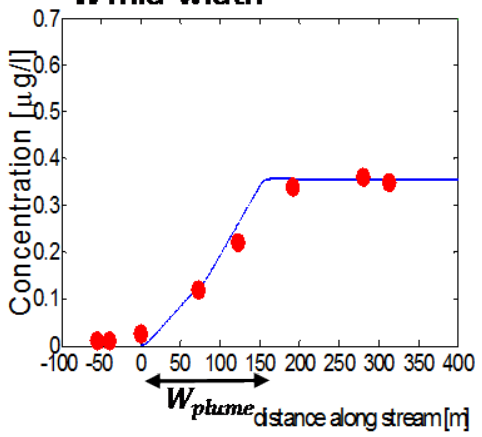

Figure 6. Plume discharged over a length of the stream bank with a uniform (a), a Gaussian (b) and a non-uniform (c) initial concentration distribution. $d$-f show the vinyl chloride concentration distribution in Grindsted stream obtained with the three distributions. g-i show the concentration in the middle of the stream's width for the three distributions, and the field data. 
a. UNIFORM

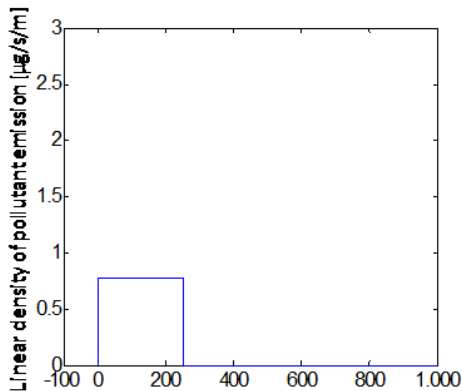

d.

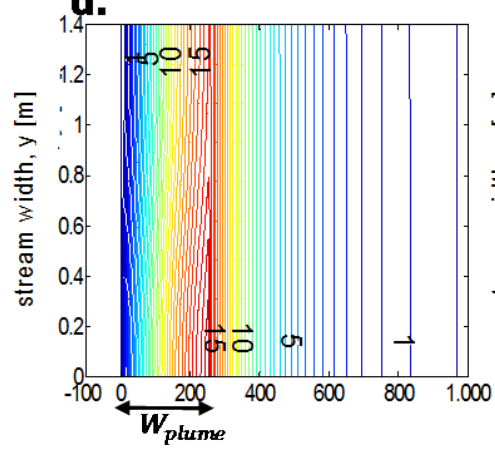

g. mid-width

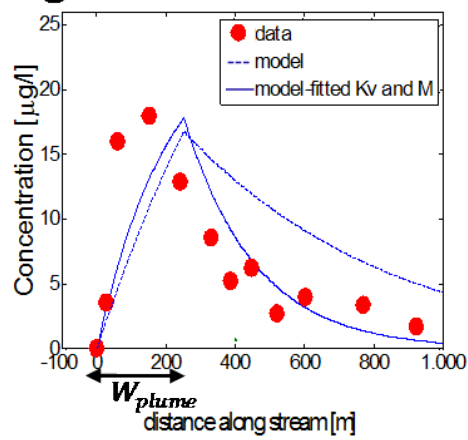

b. GAUSSIAN

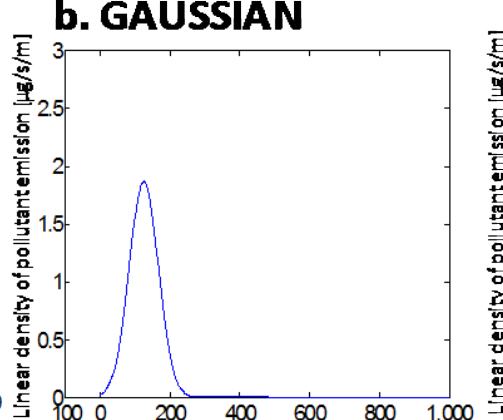

e.

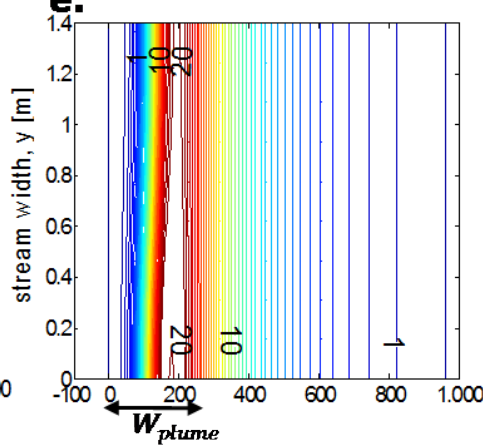

h. mid-width

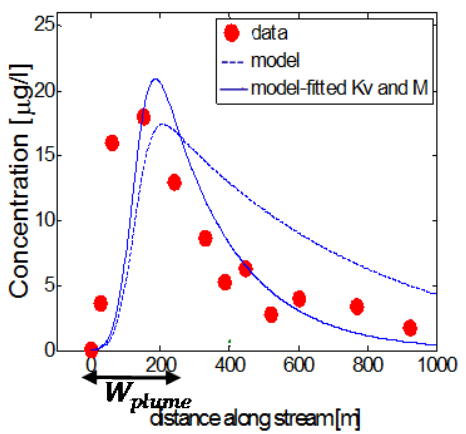

\section{c. NON-UNIFORM}
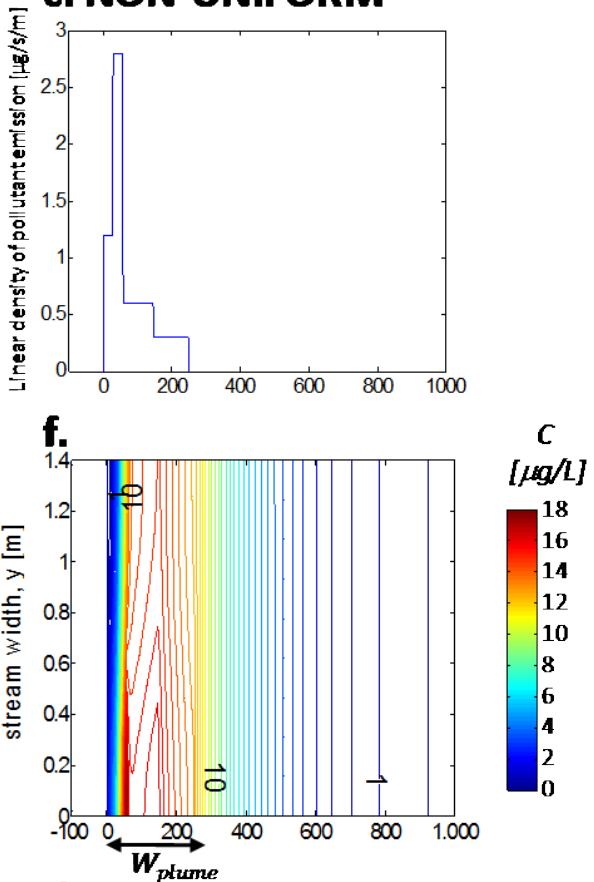

i. mid-width

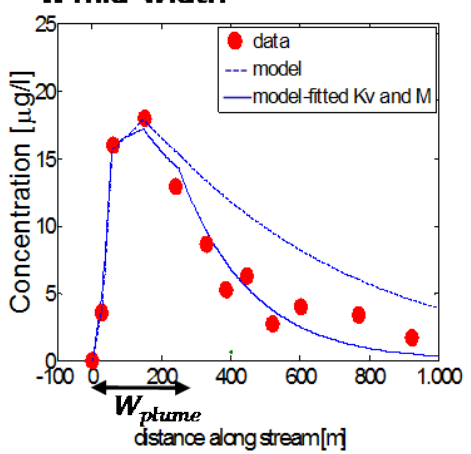

Figure 7. Plume discharged over a length of the stream bank with a uniform (a), a Gaussian (b) and a non-uniform (c) initial concentration distribution. d-f show the TCE concentration distribution in Skensved stream obtained with the three distributions. In a-f the best fit values are used $\left(K_{V}=2 \cdot 10^{-4} s^{-1}\right.$ and $\left.\dot{\mathbf{M}}=195 \mu \mathrm{g} / \mathrm{L}\right)$. g-i show the field observations and the concentration in the middle of the stream's width for the three distributions, with the Southworth estimated $\mathbf{K}_{\mathrm{V}}=7 \cdot \mathbf{1 0}^{-5} \mathrm{~S}^{-1}$ and $\dot{\mathbf{M}}=130 \mu \mathrm{g} / \mathrm{L}$ and the best fitted values $\left(\mathrm{K}_{\mathrm{V}}=2 \cdot 10^{-4} \mathrm{~s}^{-1}\right.$ and $\left.\dot{\mathbf{M}}=195 \mu \mathrm{g} / \mathrm{L}\right)$..

\subsection{Use of stream dilution models in regulatory practice}

The dilution model can estimate the concentrations at any point in the stream and the location where fully mixed conditions are achieved and can be used in a regulatory context to evaluate contaminated groundwater plume discharges into streams. To control point source releases into 
surface waters, a “combined approach” has been developed (WFD-EC, 2000) which regulates both the pollutant concentrations at the end of the pipes (emission limited values, ELM), and the concentration at the receiving water bodies by setting environmental quality standards (EQS). The EQS should not be exceeded beyond an allocated impact zone, the "mixing zone" (Directive, 2008/105/EC). In order to ensure that the extent of the mixing zone is restricted to the proximity of the discharge point, it is recommended that the size of the mixing zone is $10 \times W$, where $W$ is the width of the river (EC-Mixing Zone Guidelines, 2010). These guidelines for point source discharge can be adapted for the groundwater plume discharge, by setting the length of the mixing zone at a distance downstream of the most upstream end of the plume equal to $W_{\text {plume }}+10 \times W$ and at the bank. This distance considers the size of the stream, the width of the groundwater plume and prevents large stream sections being exposed to high concentrations.

The EU guidelines (EC-Mixing Zone Guidelines, 2010) for point source discharges, suggest that in complex cases a more detailed assessment may be required, involving the use of computerbased modeling techniques that calculate the spatial and temporal variation of the concentration. For cases where groundwater plume discharged in streams, the dilution model presented in this paper can be used.

From a regulatory point of view for risk assessment, the values of interest are $C_{\text {mix }}, C_{\max }$ and $L_{\text {mix }}$ (Figure 8). $C_{\text {mix }}$ and $C_{\max }$ provide the fully mixed and maximum stream concentrations respectively and can be compared with guideline values for stream water quality. Lmix can be used in risk assessment to direct the location of stream water quality sampling. The calculation of $C_{\max }$ (Equation (7)) is more complex and requires more input data than the calculation of $C_{\text {mix }}$, but is not always necessary since in some scenarios $C_{\max }$ equals $C_{\text {mix }}$ and $L_{\text {mix }}=0$. As shown in Figure 8a, the three parameters have a different significance for each case study, with results depending on the stream and groundwater plume characteristics. The highest values of $C_{\max }$ are usually found in 
streams with high flow and large mass discharges, while for many small streams $C_{\text {max }}$ equals $C_{\text {mix }}$ (e.g., stream A in Figure 8a). Moreover, it is possible to investigate the size of and the relation between $L_{\text {mix }}, C_{\text {mix }}$ and $C_{\max }$ for different plume and stream characteristics. We investigated this for Danish streams types, which were divided in small $(\mathrm{W}<2 \mathrm{~m})$, medium $(2 \mathrm{~m}<\mathrm{W}<10 \mathrm{~m})$ and large (W>10 m) according to Danish conditions. A Monte Carlo sensitivity analysis was performed to evaluate the mean and standard deviation of $L_{\text {mix }}, C_{\text {mix }}$ and $C_{\max }$ for each stream type and combinations of contaminant discharge and plume widths. The results showed that for small and medium Danish streams, $C_{\max }$ approximates $C_{\text {mix }}$, while for large Danish streams the value of $C_{\text {max }}$ was different from $C_{\text {mix }}$ and should therefore be calculated. It is possible to further simplify the model and the data requirements by setting the depth and width of the stream to default values (see supporting information for more details), which can be useful for screening purposes or when there is a lack of appropriate local data. A similar analysis can be performed for different ranges of stream and groundwater plume sizes. 


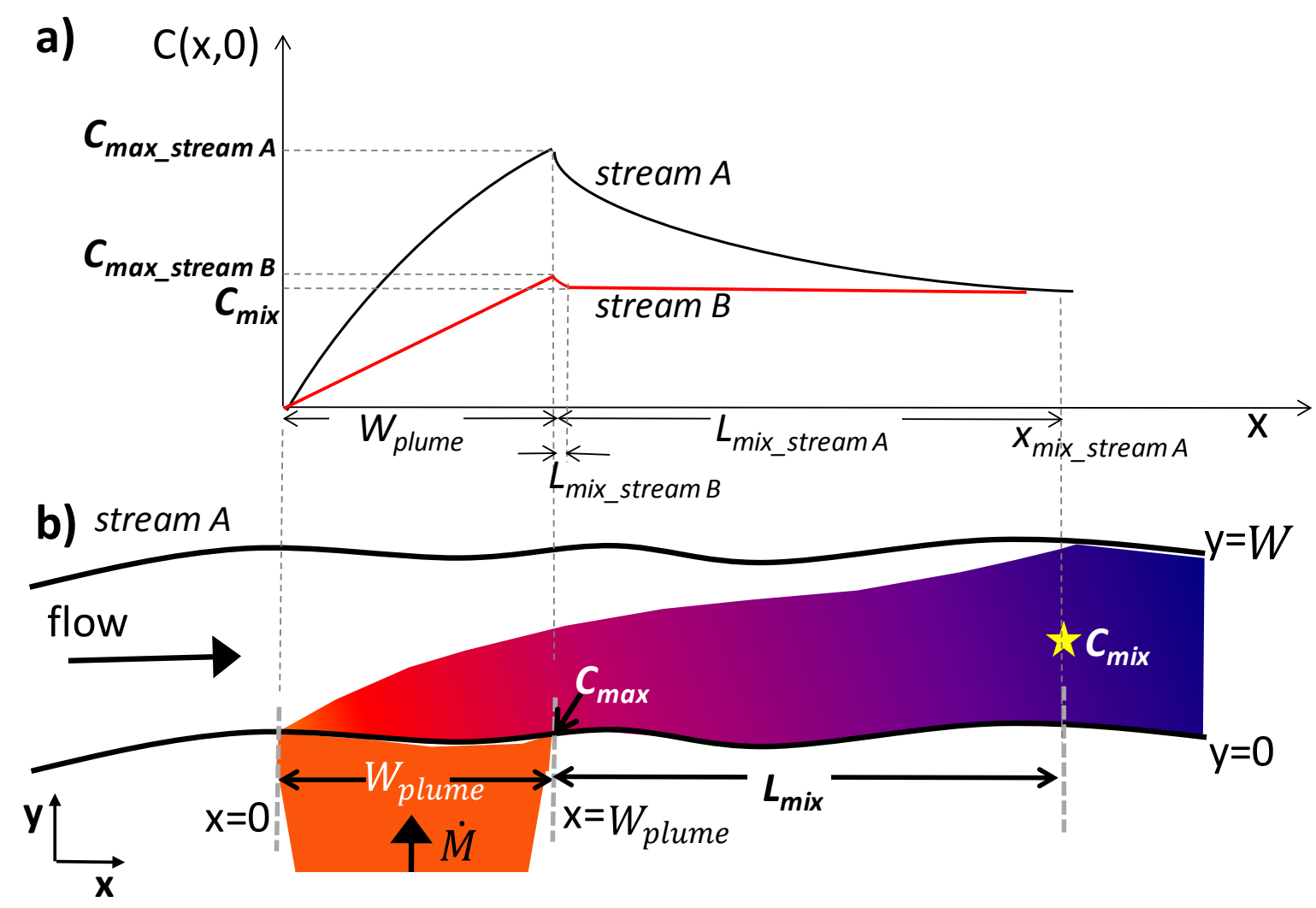

Figure 8. a) Concentration at $\mathrm{y}=0$ for two stream types $\mathrm{A}$ and $\mathrm{B} ; C_{\text {max }}, C_{\text {mix }}$ and $L_{\text {mix }}$ are shown. It is assumed that the plume is discharged at the bank with uniform concentration distribution. b) Location of $C_{\text {max }}, C_{\text {mix }}$ and $L_{\text {mix }}$ for stream $A$.

\subsection{Model assumptions, data needs and further development}

The analytical solutions presented are designed to assess the risk of streams by groundwater contaminant plumes. The analytical solution applies for a constant flow and mass discharge but these can vary significantly during the year (Schmidt et al. 2010). For risk assessment it is recommended to use the annual minimum flow in stream. Since the time scales to reach steady state in the stream are small compared to the time scales of stream flow or groundwater mass discharge, it is possible to use the model for periods with different flows or mass discharges to consider the effect of variations in both parameters.

The groundwater system can be highly variable and its hydrodynamic behavior erratic, depending on recharge, aquifer hydraulic heterogeneity and storage in river bank. The shape and 
flow of the plume discharged into the stream may vary, resulting in non-equilibrium behavior of the contaminant transport through the stream (e.g. Marion et al., 2008; Silva et al. 2009). Boundary conditions that deal with heterogeneous and transient aquifer boundaries, river bank effects and storage in low river bends have been proposed and implemented in the literature (e.g., Lees et al. 2000; Silva et al. 2009; Moench 1995; Gooseff et al. 2011; Pedretti et al. 2014). These mass transfer boundary conditions are usually adapted to model systems dominated by fast flow regions that receive solutes from less mobile regions. In this work the source is modelled as an immobile mass entering the stream. These additional effects were not implemented in the model presented in this paper because our aim was to develop a simple model for risk assessment, with small data needs.

Natural streams are not rectangular channels, which complicates the analysis. The dilution models are developed for straight channels, which limits the mixing; addition of bends will decrease the mixing length by increasing the magnitude of diffusion coefficients (Fukuoka and Sayre 1973). Moreover, the model assumes that the channel cross sectional geometry is uniform and the river bed is straight. Incorporating varying river characteristics such as morphology and vegetation into the model would require site specific data, which are often not available and the introduction of variable parameters (Guymer 1998; Marsili-Libelli and Giusti 2008), thus complicating the simple model structure.

Transverse mixing processes can be described by the transverse diffusion coefficient, $e_{t}$ which is affected by the river sinuosity, local curvature, river width, depth, discharge, river shear velocity and ice cover. Numerous studies propose theoretical equations to predict how the transverse diffusion coefficient varies with stream geometry and flow conditions (e.g., Bansal 1971; Yotsukura and Sayre 1976; Sanders et al. 1977; Fischer et al. 1979; Rutherford 1994; Jeon et al. 2007), which can result in significantly different concentration distributions and mixing lengths. In fact only in-situ tracer tests can reliably estimate this parameter, but these are logistically difficult 
and expensive. Some of the equations proposed require values for the sinuosity, radius of curvature and the roughness coefficient of the stream, which are difficult to obtain. The risk assessment model employs a simple and conservative approach to evaluate the transverse dispersion coefficient $\left(e_{t}=0.3 u^{*} \mathrm{~d}\right)$, as proposed by Fischer et al. (1979) and Rutherford (1994) and which is based on a large number of published field studies. The coefficient used (0.3) is the smallest coefficient from the range of coefficients proposed by Fischer et al. (1979), and the smallest one for a "meandering" channel proposed by Rutherford (1994), which will result in a more conservative solution.

If a detailed site assessment is required, a numerical model could be used to incorporate the variability of the parameters characterizing the pollutant transport along the length of the river, the width and depth.

A prerequisite for using the model is the availability of site specific data for the stream parameters (discharge, depth, width, slope and temperature), the groundwater plume parameters (mass discharge, width, molecular weight of compound) and the wind speed at $10 \mathrm{~m}$ above the surface of the water. For many streams it is easy to obtain a representative value for the average stream discharge, bed slope, the temperature and the wind speed from databases. It is often more difficult to map the contaminated groundwater plume, and both site specific mass discharge and plume width data are needed to determine the location of plume discharge to the stream, and to identify $\mathrm{x}=0$ and the plume width (Figure 8). It must be kept in mind that all these parameters are inherently uncertain, and this uncertainty can affect the results such as the value of the mixing length and recommended point of compliance (Equation (12))

\section{Conclusions}

The model presented in this study is a simple convolution of the model of Fischer et al. (1979) and the main contribution is the application to groundwater discharge to streams and the addition of 
volatilisation. The model is designed for the risk assessment of streams contaminated by groundwater plumes and considers the most important characteristics of the discharge of groundwater plumes in streams and processes leading to the dilution and volatilisation of contaminants in open channel flows. Comparison of the model with observed data showed that it can successfully describe the main trends and provide valuable information on the risk posed by different groundwater plumes to the stream, such as the peak concentration in the stream, the mixing length and recommendations for location of the point of compliance. In contrast the existing point source model provides a fundamentally different output and fails to describe the mixing length and concentration distribution near the plume discharge. The presented model does not require many additional parameters. Detailed knowledge of the characteristics of groundwater plume discharge, such as the distribution of contaminant mass discharge along the banks or the location of the plume discharge were shown not to be important. Volatilisation was considered and was found to be significant in shallow streams; the general trend of concentration distribution in the stream was not described when volatilisation was neglected and the maximum concentration achieved was one order of magnitude higher. In the context of risk assessment it is recommended to use the analytical solution with a uniform concentration distribution along the stream bank. Due to its ability to describe observed field data and its simplicity, the proposed approach is suitable for regulatory use and has recently been implemented in the risk assessment tool developed by the Danish EPA in response to the EU Water Framework Directive (Aisopou et al., 2014). Similar solutions are already widely used in the EU for assessing point source input (e.g., pipe discharges to rivers) (EC-Mixing Zone Guidelines, 2010). Finally, the analytical model has an important practical purpose because it can be used to identify groundwater discharge zones from stream data. This can be used to determine sampling locations in detailed monitoring campaigns, which can support advanced numerical modelling and implementation of remediation strategies. 


\section{Acknowledgement}

This project was conducted as part of a project to develop a risk assessment tool for Danish surface waters in risk of contamination from contaminated groundwater plumes and was supported by the Danish Environmental Protection Agency. Collection of field data from the Grindsted site was supported by the consulting company Orbicon and the Region of Southern Denmark. 


\section{Figure captions}

Figure 1. Conceptual model of the physical system analyzed in this study: groundwater plume of width equal to $\mathrm{W}_{\text {plume }}$ discharged in the stream of width $\mathrm{W}$.

Figure 2. Conceptual models for groundwater plume discharged at: a) a point at the side of the stream $(x=0, y=0), b)$ along a length of the bank (plume width $\left.=\mathrm{W}_{\text {plume}}\right)$, and $\mathrm{c}$ ) along a length at the half stream bed. $x=0$ is at the point located at the most upstream point of plume discharge. For a) and b) the concentration is assumed uniform in the vertical direction.

Figure 3. Contaminant plume discharged in the side of the stream; three mass discharge distributions are considered i) Gaussian, ii) uniform, and iii) non-uniform.

Figure 4. Vinyl chloride concentration distribution in Grindsted stream obtained when the contaminant is discharged at a point at the side of the stream $(x=0, y=0)(a)$, along a length of the bank ( $\left.\mathrm{W}_{\text {plume}}\right)$, (b) and along a length at the half of the stream bed. d-f show the concentration along the longitudinal direction $(x)$ at $y=0$ (bank where contaminant is discharged), $y=W / 2$ (middle of the stream) and $\mathrm{y}=\mathrm{W}$.

Figure 5. a) Conceptual model to test if groundwater reaches the stream from the bank or half the stream bed. b) Black and white streamlines show water discharging to the stream bed and the bank of the stream, respectively. Only half of the catchment is modeled due to symmetry. $\mathrm{x}_{\text {critical }}$ is the maximum distance from the stream that a contaminant at the surface will reach the stream from the side.

Figure 6. Plume discharged over a length of the stream bank with a uniform (a), a Gaussian (b) and a non-uniform (c) initial concentration distribution. d-f show the vinyl chloride concentration 
distribution in Grindsted stream obtained with the three distributions. g-i show the concentration in the middle of the stream's width for the three distributions, and the field data.

Figure 7. Plume discharged over a length of the stream bank with a uniform (a), a Gaussian (b) and a non-uniform (c) initial concentration distribution. d-f show the TCE concentration distribution in Skensved stream obtained with the three distributions. g-i show the concentration in the middle of the stream's width for the three distributions, and the field observations.

Figure 8. a) Concentration at $\mathrm{y}=0$ for two stream types $\mathrm{A}$ and $\mathrm{B} ; C_{\max }, C_{\operatorname{mix}}$ and $L_{\operatorname{mix}}$ are shown. It is assumed that the plume is discharged at the bank with uniform concentration distribution. b) Location of $C_{\max }, C_{\operatorname{mix}}$ and $L_{\operatorname{mix}}$ for stream A. 


\section{References}

Aisopou, A, A.T. Sonne, P.L. Bjerg, and P.J. Binning (2014). "Jordforureningers påvirkning af overfladevand, delprojekt 4." Miljøproject nr. 1572, Miljøstyrelsen. ISBN nr. 978-87-9317850-2

Ani, E. C., S. Wallis, A. Kraslawski and P. S. Agachi (2009). "Development, calibration and evaluation of two mathematical models for pollutant transport in a small river."

Environmental Modelling \& Software 24(10): 1139-1152.

Bansal, M. K. (1971). "Dispersion in natural streams." J. Hydraul. Div. ASCE 97(11): 1867-1886.

Bianchin, M., L. Smith, J. F. Barker and R. Beckie (2006). "Anaerobic degradation of naphthalene in a fluvial aquifer: A radiotracer study." Journal of Contaminant Hydrology 84(3-4): 178196.

Cadena, F., G. A. Eiceman and V. J. Vandiver (1984). "Removal of volatile pollutants from rapid stream.” Water Pollution Control Federation, 56(5): 460-463

Chambon, J. C., P. J. Binning, P. R. Jorgensen and P. L. Bjerg (2011). "A risk assessment tool for contaminated sites in low-permeability fractured media." Journal of Contaminant Hydrology 124(1-4): 82-98.

Chapman, S. W., B. L. Parker, J. A. Cherry, R. Aravena and D. Hunkeler (2007). "Groundwatersurface water interaction and its role on TCE groundwater plume attenuation." Journal of Contaminant Hydrology 91(3-4): 203-232.

Chen, F., D. L. Freedman, R. W. Falta and L. C. Murdoch (2012). "Henry's law constants of chlorinated solvents at elevated temperatures.” Chemosphere 86: 156-165

Conant, B., J. A. Cherry and R. W. Gillham (2004). "A PCE groundwater plume discharging to a river: influence of the streambed and near-river zone on contaminant distributions." Journal of Contaminant Hydrology 73(1-4): 249-279.

Dahi, E., H. Løkke, B. Jensem, J. Andersen, K. Broholm, J. K. Pedersen. And L. Husmer, (1989), "Fordampning" in Lærebog i vandforurening med miljøgifte, ed. E. Dahi, 1st edn, Polyteknisk Forlag, Denmark: 67-92

Elhadi, N., A. Harrington, I. Hill, Y. L. Lau and B. G. Krishnappan (1984). "River Mixing - A state of the art report." Canadian Journal of Civil Engineering 11(3): 585-609.

Ellis, P. A. and M. O. Rivett (2007). "Assessing the impact of VOC-contaminated groundwater on surface water at the city scale." Journal of Contaminant Hydrology 91(1-2): 107-127.

European Commission (2000). Directive 2000/60/EC of the European Parliament and of the Council of 23 October 2000 establishing a framework for Community action in the field of water policy. Official Journal of the European Communities L 327:1-72.

European Commission (2008). Directive 2008/105/EC of the European Parliament and of the Council of 16 December 2008 on environmental quality standards in the field of water policy, amending and subsequently repealing Council Directives 82/176/EEC, 83/513/EEC, 84/491/EEC, 86/280/EEC and amending Directive 2000/60/EC of the European Parliament and of the Council, EUWFD (European Commission Water Framework Directive), Official Journal of the European Communities L 348: 84-97.

European Commission (2010). EU EQSD CIS Technical Guidance Document - Technical Guidelines for the identification of mixing zones pursuant to Art 4(4) of the Directive 2008/105/EC.

Fischer, H. B., E. J. List, R. C. Y. Koh, J. Imberger and N. H. Broooks (1979). Mixing in inland and coastal waters. San Diego, Academic Press. 
Flyvbjerg, J. and A. Damborg (1994). ”Jernhyt Bæk: Vurdering af skæbne og effekt af klorerede alifater”, Danmarks Geologiske Undersøgelser, pp. 8-11.

Fukuoka, S. and W. W. Sayre (1973). "Longitudinal Dispersion in Sinuous Channels." Journal of the Hydraulics Division 99(1): 195-217.

Gooseff, M.N., D.A. Benson, M.A. Briggs, M. Weaver, W. Wollheim, B. Peterson, C.S. Hopkinson (2011). "Residence time distribution in surface transient storage zones in streams:

Estimation via signal deconvolution.” Water Resources Research, 47, W05509, doi:10.1029/2010WR009959.

Guymer, I. (1998). "Longitudinal dispersion in sinuous channel with changes in shape." Journal of Hydraulic Engineering-Asce 124(1): 33-40.

Hancock, P. J. (2002). "Human impacts on the stream-groundwater exchange zone." Environmental Management 29(6): 763-781.

Hunt, B. (1978). “Dispersive Source in Uniform Ground-water Flow.” ASCE Journal Hydraulic Division 104(1): 75-85

Jeon, T. M., K. O. Baek and I. S. Seo (2007). "Development of an empirical equation for the transverse dispersion coefficient in natural streams." Environ. Fluid Mech. 7: 317-329.

Jirka, G. H. and V. Weitbrecht (2005). Mixing models for water quality management in rivers: continious and instantaneous pollutant releases. Water Quality Hazards and Dispersion of Pollutants. W. Czernuszenko and P. M. Rowinski. New York, Springer: 1-34.

Kalinowska, M. B. and P. M. Rowinski (2012). "Uncertainty in computations of the spread of warm water in a river - lessons from Environmental Impact Assessment case study." Hydrology and Earth System Sciences 16(11): 4177-4190.

Lees, M.J., L.A. Camacho, S. Chapra, (2000). “On the relationship of transient storage and aggregated dead zone models of longitudinal solute transport in streams.” Water Resources Research, 36(1), 213-224.

Liss, P.S. and P.G. Slater (1974). "Flux of gases across air-sea interface", Nature, 247(5438): 181184.

Lung, W. S. (1995). "Mixing-zone modeling for toxic waste-load allocations." Journal of Environmental Engineering-Asce 121(11): 839-842.

Marion, A., M. Zaramela, A. and A. Bottacin-Busolin. (2008). "Solute transport in rivers with multiple storage zones: the STIR model.” Water Resour. Res. 44, W10406, doi:10.1029/2008WR007037

Marsili-Libelli, S. and E. Giusti (2008). "Water quality modelling for small river basins." Environmental Modelling \& Software 23(4): 451-463.

McKnight, U. S., S. G. Funder, J. J. Rasmussen, M. Finkel, P. J. Binning and P. L. Bjerg (2010). "An integrated model for assessing the risk of TCE groundwater contamination to human receptors and surface water ecosystems." Ecological Engineering 36(9): 1126-1137.

McKnight, U. S., J. J. Rasmussen, B. Kronvang, P. L. Bjerg and P. J. Binning (2012). "Integrated assessment of the impact of chemical stressors on surface water ecosystems." Science of the Total Environment 427: 319-331.

Mendoza, C. A. J. R. L. and R. W. Gillham, (1996), “Vapor Migration in the Vadose Zone”. Dense Chlorinated Solvents, Waterloo Press: 179-198.

Milosevic, N., N. I. Thomsen, R. K. Juhler, H. J. Albrechtsen and P. L. Bjerg (2012). "Identification of discharge zones and quantification of contaminant mass discharges into a local stream from a landfill in a heterogeneous geologic setting." Journal of Hydrology 446: 13-23. 
Moench , A. F. (1995). "Convergent radial dispersion in a double-porosity aquifer with fracture skin: Analytical solution and application to a field experiment in fractured chalk.” Water Resources Research, 31: 8, 1823-1835

Park, R. A. and S. J. Clough (2012). "Volatilization”, Technical Documentation 3(1): 237-240.

Pedretti, D., D. Fernandez-Garcia, X. Sanchez-Vila, D. Bolster, and D.A. Benson, (2014).

"Apparent directional mass-transfer capacity coefficients in three-dimensional anisotropic heterogeneous aquifers under radial convergent transport.” Water Resources Research, doi: 10.1002/2013WR014578

Pujol, L. and J. A. Sanchez-Cabeza (2000). "Use of tritium to predict soluble pollutants transport in Ebro River waters (Spain)." Environmental Pollution 108(2): 257-269.

Runkel, R. L. (1998). One-dimensional Transport with Inflow and Storage (OTIS) - a Solute Transport Model for Streams and Rivers. Water Resources Investigations Report, United States Geological Survey. 48-4018.

Rutherford, J. C. (1994). River mixing. Chichester, UK, Wiley.

Sanders, T. G., D. D. Adrian and J. M. Joyce (1977). "Mixing lenght for representative waterquality sampling." Journal Water Pollution Control Federation 49(12): 2467-2478.

Schmidt, C., M. Martienssen and E. Kalbus (2010). "Influence of water flux and redox conditions on chlorobenzene concentrations in a contaminated streambed." Hydrological Processes 25: 234-245.

Nielsen, S.S.; Tuxen, N; Frimodt, O.; Bjerg, P.L.; Sonne, A.T; Binning, P.J.; Fjordbøge, A.S. Aabling, J. (2014). "Risikovurdering af overfladevand, som er påvirket af punktkildeforurenet grundvand.” Miljøproject nr. 1575, Miljøstyrelsen. ISBN nr. 978-8793178-54-0

Socolofsky, S.A. and G.H. Jirka (2005). Mixing in Rivers: Turbulent Diffusion and Dispersion, in Special Topics in Mixing and Transport Processes in the Environment, eds. S.A. Socolofsky and G.H. Jirka, Texa A\&M University, Texas, USA, pp. 51-71.

Southworth, G. R. (1979). "The role of volatilization in removing polycyclic aromatic hydrocarbons from aquatic environments.” Bulletin of environmental contamination and toxicology 21(45): 507-514.

Silva, O., J. Carrera, M. Dentz, S. Kumar, A. Alcolea, M. Willmann, (2009). “A general real-time formulation for multi-rate mass transfer problems.” Hydrol. Earth Syst. Sci., 13, 1399-1411

Thyssen, N., Erlandsen, M., Jeppesen, E. \& Ursin, C. (1987). "Reaeration of oxygen in shallow, macrophyte rich streams. 1. Determination of the reaeration rate coefficient.” Internationale Revue der Gesamten Hydrobiologie, vol. 72, no. 4, pp. 405-429.

Trapp, S. and B. Harland (1995). "Field test of volatilization models.” Environmental Science and Pollution Research 2(3): 38-166

Trapp, S. and M. Matthies (1998). "Part1: Text Book” in Chemodynamics and Environmental Modelling Springer, Germany: 38-166

Troldborg, M., W. Nowak, I. V. Lange, M. C. Santos and P. J. Binning (2012). "Application of Bayesian geostatistics for evaluation of mass discharge uncertainty at contaminated sites." Water Resources Research 48.

Westbrook, S. J., J. L. Rayner, G. B. Davis, T. P. Clement, P. L. Bjerg and S. T. Fisher (2005). "Interaction between shallow groundwater, saline surface water and contaminant discharge at a seasonally and tidally forced estuarine boundary." Journal of Hydrology 302(1-4): 255269.

Yotsukura, N. and W. W. Sayre (1976). "Transverse mixing in natural channels." Water Resour. Res. 12(4): 695-704. 
Zhang, W. and D. Z. Zhu (2011). "Near-Field Mixing Downstream of a Multiport Diffuser in a Shallow River." Journal of Environmental Engineering-Asce 137(4): 230-240. 